\title{
Effect of High Temperature Treatment on Aqueous Corrosion of Low-Carbon Steel by Electrochemical Impedance Spectroscopy*
}

\author{
Samuel J. Gana ${ }^{1}$, Nosa O. Egiebor ${ }^{1}$, Ramble Ankumah ${ }^{2}$ \\ ${ }^{1}$ Environmental Engineering Program, Chemical Engineering Department, Tuskegee University, Tuskegee, USA; ${ }^{2}$ Department of \\ Agricultural and Environmental Sciences, Tuskegee University, Tuskegee, USA. \\ Email: Egiebor@tuskegee.edu
}

Received December $28^{\text {th }}, 2010$; revised January $11^{\text {th }}, 2011$; accepted January $16^{\text {th }}, 2011$.

\begin{abstract}
The corrosion behavior of $1020 \mathrm{C}$ carbon steel samples that had been subjected to oxidizing heat treatment at $550^{\circ} \mathrm{C}$ and $675^{\circ} \mathrm{C}$ were studied in sodium chloride electrolytes using a 3-electrode electrochemical impedance spectroscopy. Experimental data were used to evaluate the corrosion behavior of the samples while optical microscopy was employed to investigate the surface characteristics of the samples before and after aqueous corrosion. The results showed that while the sample treated at $550^{\circ} \mathrm{C}$ revealed an increasing corrosion rate with time, the sample treated at $675^{\circ} \mathrm{C}$ indicated a higher initial corrosion rate, but the rate declined gradually over the 4-day experimental period. Optical microscopy revealed significant formation of surface corrosion products on both heat treated samples, but the complex plane diagrams indicated significant capacitive behavior for the heat treated samples relative to the untreated samples.
\end{abstract}

Keywords: Impedance, Carbon Steel, Corrosion, Nyquist Diagrams, Photomicrographs

\section{Introduction}

The corrosion behavior of carbon and stainless steels in service under high temperature conditions has become a subject of major research interest for a number of industrial applications $[1,2]$. Temperature is one of the critical environmental parameters in corrosion studies because of its severe effects on physicochemical and electrochemical reaction rates. Accordingly, passive film stability and solubility, pitting and crevice corrosion behavior are known to be closely related to temperature [3]. Elevated temperature corrosion is a widespread problem in various industries, including; nuclear power generation, petrochemical, fossil fuel power generation, waste incineration, pulp and paper, and numerous other industrial processes. In a number of industries where components operate at high temperatures, severe corrosion is encountered due to the significant changes in the surface chemistry of the service materials. In cases where desirable higher operating temperatures lead to an increase in process efficiency, the process is impeded by an exponential increase in corrosion potential of structural materials with tem-

\footnotetext{
*Thanks to US Department of Energy/NNSA Massie Chair program.
}

perature.

For example, in the development of the next generation (Generation IV) of advanced nuclear reactors [4], some of the reactor systems, such as the very high temperature reactors (VHTR), will operate at coolant temperatures above $1000^{\circ} \mathrm{C}$. Such severe temperature environments present major materials degradation and corrosion challenges in terms of maintaining the mechanical and chemical stability of the candidate structural materials. For most structural materials including carbon and stainless steels, the breakdown of the protective oxide layer at high temperatures is attributable to numerous degradation and defect formation phenomena. Some of these protective film degradation processes include loss of a critical surface concentration of a solute needed to maintain film stability, swelling, growth mechanisms of surface product, formation of pores at the film-substrate interface, and oxide layer spallation [5]. The development of imperfections in the substrate also limits the effectiveness of the protective oxide films under extreme conditions. All of these degradation processes contribute to the general corrosion, pitting corrosion, stress corrosion cracking, corrosion fatigue, and hydrogen-induced cracking and 
embrittlement.

Attempts to solve these high temperature materials corrosion and degradation processes have included the development of new materials through engineered microstructure evolution and alloy formulation by refractive element inclusion in conventional steel compositions [4]. The mechanical inclusion of Y-Ti-O nano-particles into $\mathrm{Fe}-\mathrm{Cr}$ based ferritic alloy was reported by Alinger et al. [6] to impart remarkably high temperature stability with limited nanocluster growth and coarsening. These materials, now generally referred to as oxide dispersion strengthened (ODS) steels, are believed to have excellent potential for corrosion and degradation resistance at high temperatures due to their unique nanostructures. In other studies, the addition of Si powders was reported to cause the formation of a duplex microstructure in austenitic stainless steels with significant increases in the aqueous corrosion resistance of the resulting alloys $[7,8]$. However, the exact mechanisms responsible for the apparent thermal stability of the materials resulting from their unique nanostructures are not known.

While the development of new materials that are corrosion resistant at high temperatures is critical, one of the major scientific challenges that have not been fully addressed is the fundamental understanding of the electrochemical mechanisms for corrosive environmental degradation that limit the effective use of structural steel materials in extreme temperature environments. Meeting this challenge will require a basic and systematic study of the effects of high temperature treatment on the corrosion behavior of a variety of structural steel materials, including carbon steel, stainless steel, and various specialty steels that are candidate materials for high temperature service. This will enable a fundamental understanding of the influence of various alloying components and nanostructure developments on the corrosion resistance of materials at high temperatures.

The study reported here represents a subset of a larger study aimed at conducting a systematic investigation of the effects of high temperature treatments on the aqueous corrosion behavior of a number of structural steel materials with the hope of providing a basic understanding of how chemical composition and nanostructure developments impact on corrosion behavior. The aim of the current communication was to study the effects of high temperature oxidative treatments on the aqueous corrosion of $1020 \mathrm{C}$ low-carbon steel in $\mathrm{NaCl}$ electrolyte, using electrochemical impedance spectroscopy. The specific objective was to investigate the corrosion behavior of $1020 \mathrm{C}$ low-carbon steel that had been pretreated in an oxidizing atmosphere at either $550^{\circ} \mathrm{C}$ or $675^{\circ} \mathrm{C}$ in comparison to untreated samples. The study was based on the simple hypothesis that higher oxidative heat treatment temperatures should result in higher aqueous corrosion rates for low carbon steel.

\section{Experimental}

The 1020C carbon steel specimens used in this study were obtained from Metal Samples Company of Munford, Alabama, USA with nominal chemical composition as follows: $\mathrm{Mn} 0.450, \mathrm{Al} 0.046, \mathrm{Cr} 0.003, \mathrm{~N} 0.005$, As 0.003, Cu 0.005, Si 0.017, Ni 0.003, C 0.020, P 0.012, Fe 99.437. Some of the samples were subjected to heat treatment in air in a muffle furnace by isothermally heating each sample to either $550^{\circ} \mathrm{C}$ or $675^{\circ} \mathrm{C}$, and held at the treatment temperatures for 1.0 hour. The untreated (control) and heat treated specimens were subsequently employed as the working electrodes for electrochemical measurements, with 3 wt.\% $\mathrm{NaCl}$ solution used as electrolyte.

The electrochemical impedance spectroscopy (EIS) equipment used in the experiment was a Princeton Applied Research (PAR) Potentiostat Model 263A, employing a 3-electrode configuration in a Princeton Applied Research model K0235 flat electrochemical cell with a platinum counter electrode, and a $\mathrm{Ag}-\mathrm{AgCl} / \mathrm{KCl}$ (saturated) reference electrode. The software used for data acquisition and analyses was a Princeton Applied Research (PAR) PowerSuite electrochemical application software. Electrochemical tests on the samples were setup and conducted in a three-electrode configuration. The samples, at the specified electrolyte concentration, were studied for 4 days. The metal samples were exposed to the electrolyte solution through a fixed orifice of $1.0 \mathrm{~cm}^{2}$ surface area. The reference electrode was submerged in the $\mathrm{Ag}-\mathrm{AgCl} / \mathrm{KCl}$ saturated solution. An alternating current of $10 \mathrm{mV}$ was applied to the electrode under study at sweeping frequencies of between $0.1 \mathrm{~Hz}$ and $100 \mathrm{kHz}$. The frequency response of the electrode under the different test conditions were recorded and displayed as Nyquist plots for further analysis. Corrosion data were collected continuously for 4 days before the experiments were terminated for data analyses. The equipment software was also used to generate data for the corrosion rates, open circuit potentials, polarization resistance, and polarization curves or Tafel plots.

For optical micrographic examinations, the untreated control samples were first polished using a Munnimet polisher. The samples were subjected to an initial polishing with 240 or 320 -grit SIC paper under a MetaDi fluid at $35 \mathrm{rpm}$ speed in the polisher. The samples were then successively polished with 9-micron MetaDi Supreme diamond suspensions with UltraPol cloth, 3-microm with Trident cloth, and 0.5-micron MasterPrep alu- 
mina suspension on a MicroCloth. All polishings were conducted at $5 \mathrm{lbs}$ pressure, 20-30 rpm for between 3 and 5 minutes each. The samples were finally etched using $2 \%$ Nital ( $2 \mathrm{~mL}$ nitric acid, $98 \mathrm{~mL}$ ethanol). The samples were immersed at 10 -second intervals and cleaned with ethanol after etching, before subsequent examination under an optical microscope. The optical microscope used was a Wild Heerbrugg M3Z optical microscope equipped with a Paxit digital camera.

\section{Results and Discussions}

Figure 1 presents the photomicrograph of the untreated $1020 \mathrm{C}$ low carbon steel sample. As expected, the figure shows a typical $\alpha$-ferrite grain structure. Figure 2 shows the open circuit potential (OCP) plot with time, while Figure 3 presents the polarization resistance plot with time $\left(R_{p}\right)$ for the control sample as well as the samples treated at $550^{\circ} \mathrm{C}$ and $675^{\circ} \mathrm{C}$. Figure 2 demonstrates that the control sample and the sample treated at $675^{\circ} \mathrm{C}$ have similar OCP trends throughout the 4-day experimental period. The OCP for both samples decreased from about $-0.725 \mathrm{~V}$ after day- 1 to about $-0.745 \mathrm{~V}$ in day- 4 . In contrast, the sample heated at $550^{\circ} \mathrm{C}$ showed a significantly higher OCP of between $-600 \mathrm{~V}$ and $-625 \mathrm{~V}$ throughout the 4-day period. These results suggest a higher equilibrium rate of corrosion for the sample treated at $550^{\circ} \mathrm{C}$ than both the untreated sample and the one treated at $675^{\circ} \mathrm{C}$.

The results presented in Figure 3 shows that the initial polarization resistance $\left(\mathrm{R}_{\mathrm{p}}\right)$ for the $550^{\circ} \mathrm{C}$ sample was significantly higher than those of the control and the sample treated at $675^{\circ} \mathrm{C}$. However, the $R_{p}$ for the $550^{\circ} \mathrm{C}$ sample continued to decline throughout the 4-day experimental period, going from $2800 \mathrm{Ohms} / \mathrm{cm}^{2}$ on day-1 to about $1900 \mathrm{Ohms} / \mathrm{cm}^{2}$ on the 4-day. In contrast, the $\mathrm{R}_{\mathrm{p}}$ for the $675^{\circ} \mathrm{C}$ sample showed continuous increase from about $1400 \mathrm{Ohms}$ on day-1 to $2100 \mathrm{Ohms}$ on 4-day. The declining polarization resistance with time for the $550^{\circ} \mathrm{C}$ sample suggests a decreasing passivation, and therefore increasing corrosion rate with time for this sample, while the $675^{\circ} \mathrm{C}$ sample demonstrates an opposite trend of increasing passivation with time, thus suggesting increasing resistance to corrosion, or decreasing corrosion rate with time. This trend was unexpected since the general belief is that the sample subjected to a more severe temperature environment will likely result in increasing susceptibility to corrosion. The control sample also showed a gradual increase in polarization resistance over the 4-day experimental period, similar to the $675^{\circ} \mathrm{C}$ treated sample.

Figure 4 presents the corrosion rate in mills per year (MPY) versus time plots for the three samples mentioned above. The results are in good agreement with the ob-

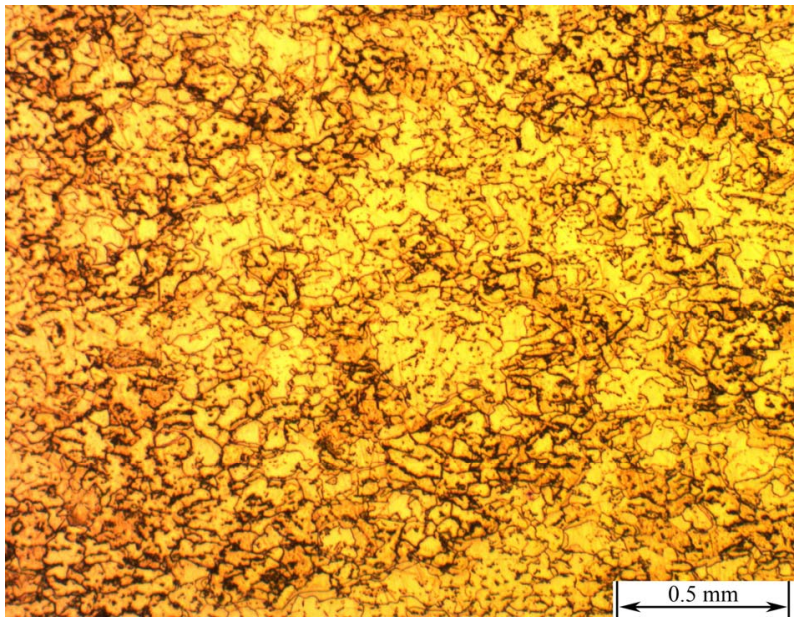

Figure 1. Photomicrograph of untreated/control 1020C carbon steel sample showing a typical $\alpha$-ferrite grain structure.

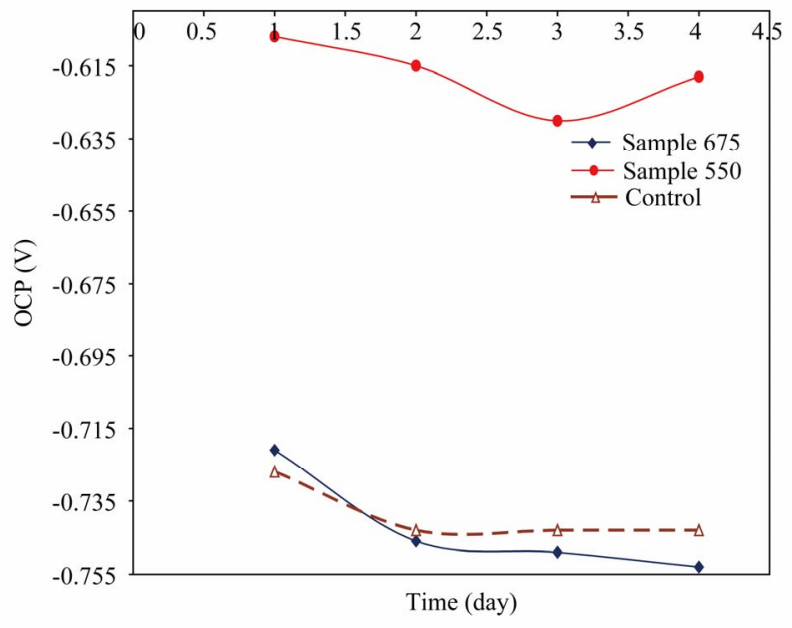

Figure 2. Open circuit potential (OCP) versus time plots for control sample and samples heat-treated at $550^{\circ} \mathrm{C}$ and $675^{\circ} \mathrm{C}$ for $1 \mathrm{hr}$ before corrosion.

served trends in the polarization resistance results of Figure 3. The initial corrosion rate for the $675^{\circ} \mathrm{C}$ sample of 27.5 MPY in day-1, declining to about 18.5 MPY after four days, while that of the $550^{\circ} \mathrm{C}$ sample increased significantly from 14.0 MPY in day-1 to about 21.5 MPY after four days. At the end of the $4^{\text {th }}$ day, the corrosion rate for the $550^{\circ} \mathrm{C}$ sample exceeded the rates for the control sample and the sample treated at $675^{\circ} \mathrm{C}$. Again this corrosion rate is unexpected as mentioned earlier. Figure 5 shows the complex plane (Nyquist plot) diagram for the untreated (control) 1020C low carbon steel sample. The figure discloses a readily corroding sample with a typical Randle cell-type semi-circular arc for each of the 3-days of experimentation. The increasing diameter of 


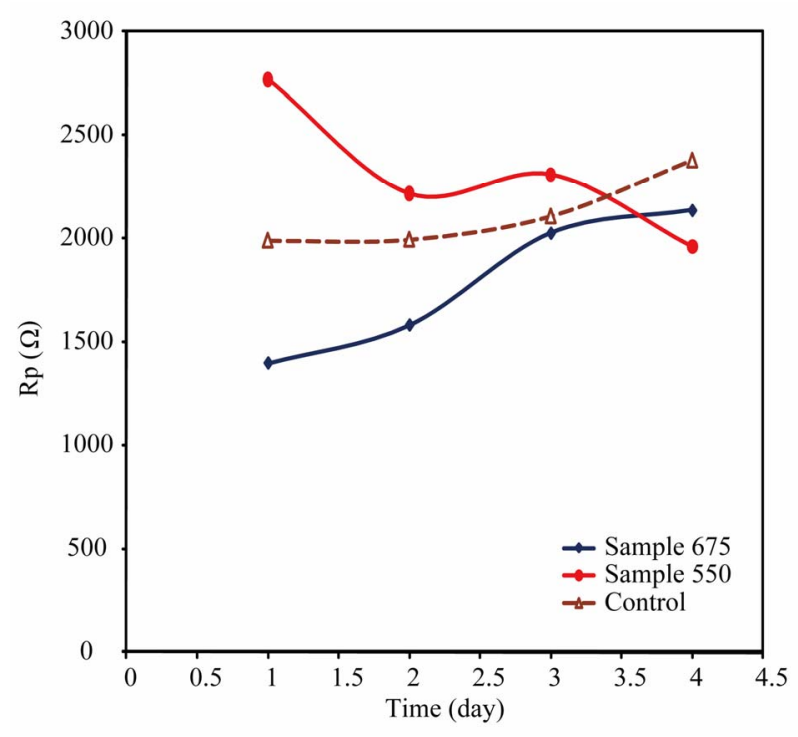

Figure 3. Polarization resistance (Rp) versus time plots for $1020 \mathrm{C}$ carbon steel control sample, and for samples heat treated at $675^{\circ} \mathrm{C}$ and $550^{\circ} \mathrm{C}$ for $1 \mathrm{hr}$ before corrosion studies.

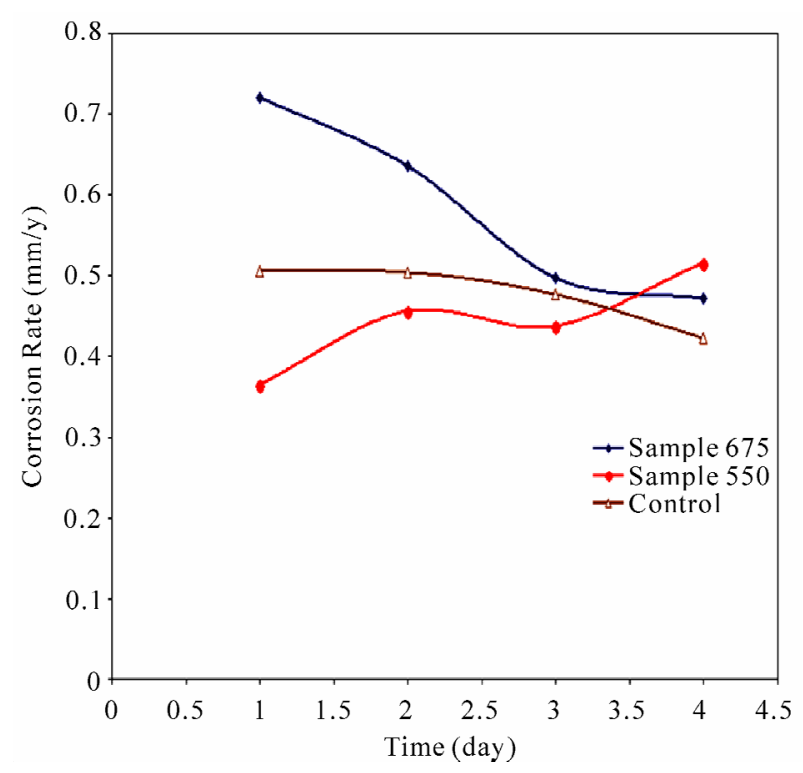

Figure 4. Corrosion rate vs. time plots for $1020 \mathrm{C}$ carbon steel control sample and for samples heat treated at $675^{\circ} \mathrm{C}$ and $550^{\circ} \mathrm{C}$ for $1 \mathrm{hr}$ before corrosion experiments.

the semi-circular arcs from day-1 to day-3 is indicative of increasing polarization resistance and decreasing corrosion rate with time. This observation of increasing diameter of the Nyquist semi-circles with time as an indication of increasing corrosion protection has also been reported by Rout [9]. These Nyquist diagrams also confirm the polarization resistance trend observed in Figure $\mathbf{3}$, and demonstrates that although the sample result indi- cate active corrosion, it continues to passivate with time. Figure 6 presents the Nyquist diagram for the low-carbon steel sample pretreated at $550^{\circ} \mathrm{C}$ for 1 hour before aqueous corrosion experimentation. In comparison to Figure 5 results, each of the Nyquist diagrams in Figure 6 shows a single capacitive arc for the sample throughout the experimental period.

This capacitive behavior illustrates that the heat treatment of the low-carbon $\alpha$-ferritic steels at $550^{\circ} \mathrm{C}$ leads to a buildup of a porous oxide layer which is not necessarily protective of the surface due to the high conductivity of the electrolytic solution inside the pores of the oxide layer. The non protective nature of this porous oxide layer is evidenced in the observed higher corrosion rate after 3 days of corrosion measurements for the $550^{\circ} \mathrm{C}$

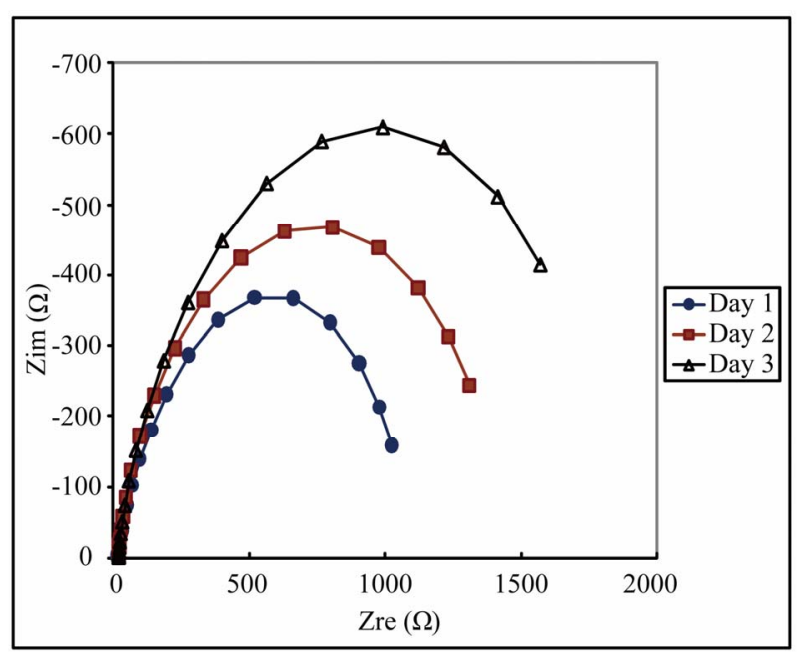

Figure 5. Complex plane (Nyquist) diagram for untreated $1020 \mathrm{C}$ carbon steel control sample.

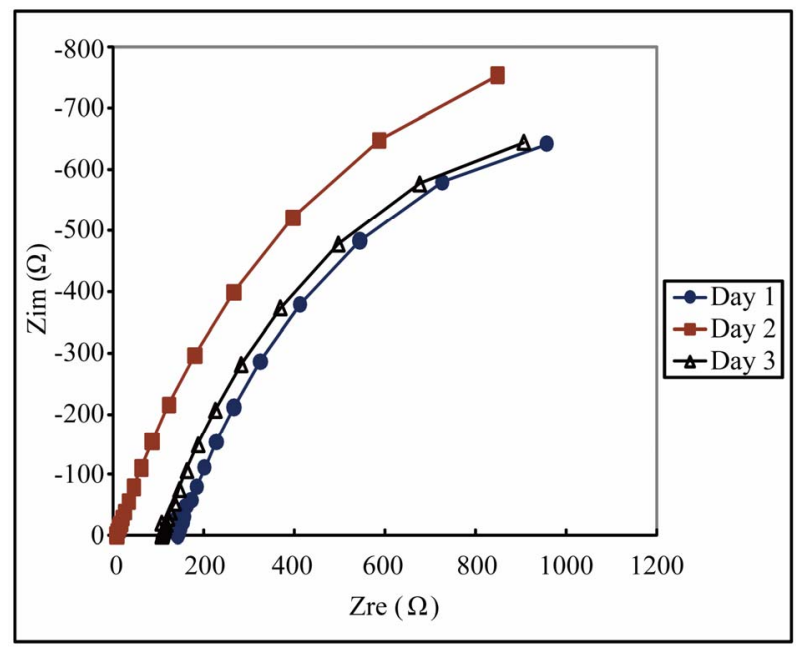

Figure 6. Complex plane or Nyquist diagram for $1020 \mathrm{C}$ low-carbon steel heat treated at $550^{\circ} \mathrm{C}$ for $1 \mathrm{hr}$. 
heat treated samples relative to the untreated sample as shown in Figure 4. This porous oxide layer is known to engender diffusion impedance through a finite thickness which leads to a capacitive arc formation in the complex plane diagram. The impedance results from the diffusion of oxygen through the surface oxide scale. Previous studies have also reported that the observed capacitive behavior of such an actively corroding sample is attributable to this porous barrier layer formation $[10,11]$. Figure 7 presents the Nyquist diagram for the low-carbon sample treated at $675^{\circ} \mathrm{C}$. The figure also show single capacitive arc for each day similar to the sample treated at $550^{\circ} \mathrm{C}$. Again this result is indicative of a porous oxide barrier layer formed on the sample surface.

The capacitance of this kind of oxide barrier layer can be related to the thickness of the barrier layer by the following equation [10]:

$$
C=\varepsilon \varepsilon_{0} S / d
$$

where $\varepsilon_{0}=8.85 \times 10^{-14} \mathrm{~F} / \mathrm{cm}$ is the dielectric constant in vacuum, $\varepsilon=$ constant depending on the material, $\mathrm{S}=$ electrode surface area. The capacitive behavior of surface oxide scales have been modeled as constant phase elements (CPE) and attributed to the redox transformation of the surface corrosion products from the ferrous to the ferric state. Figures 8 and 9 show the photomicrographs of the samples tempered at $550^{\circ} \mathrm{C}$ and $675^{\circ} \mathrm{C}$ respectively, after corrosion for 4 days in $3.0 \mathrm{wt} . \% \mathrm{NaCl}$ electrolyte.

The two figures demonstrate significant uniform surface corrosion, with some spots indicating localized or pitting corrosion. The extensive surface corrosion observed in these photomicrographs is in agreement with the corrosion and EIS data presented above.

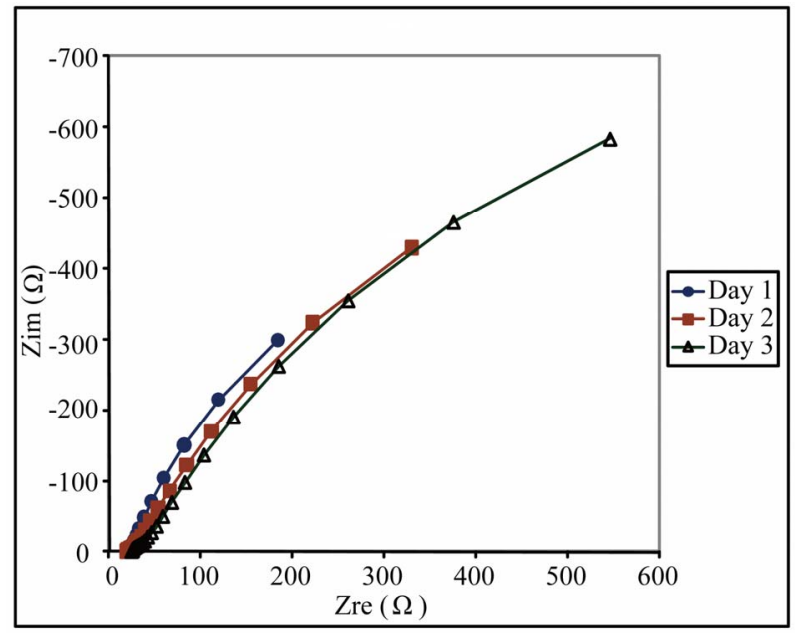

Figure 7. Complex plane or Nyquist diagram for $1020 \mathrm{C}$ low-carbon steel heat treated at $675^{\circ} \mathrm{C}$ for $1 \mathrm{hr}$.

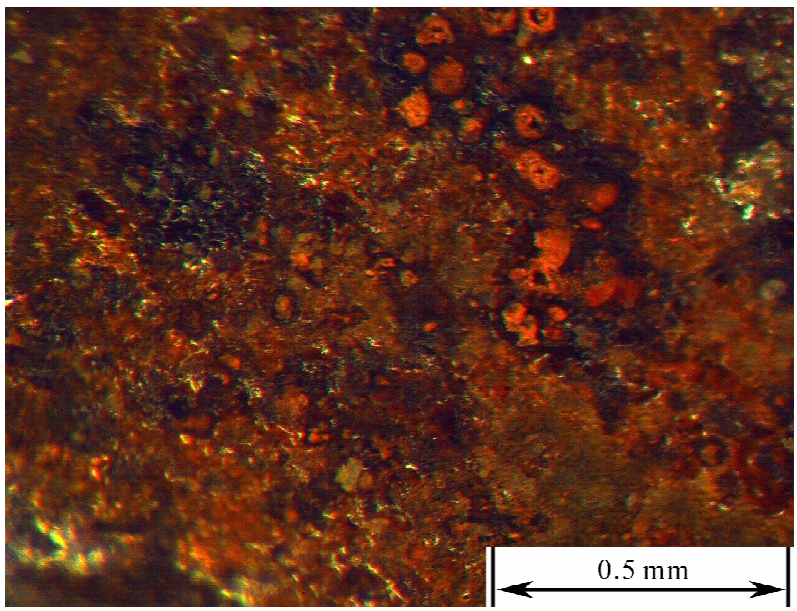

Figure 8. Photomicrograph of $1020 \mathrm{C}$ carbon steel treated at $550{ }^{\circ} \mathrm{C}$ and after 4 days of corrosion studies in 3 wt. $\% \mathrm{NaCl}$ solution.

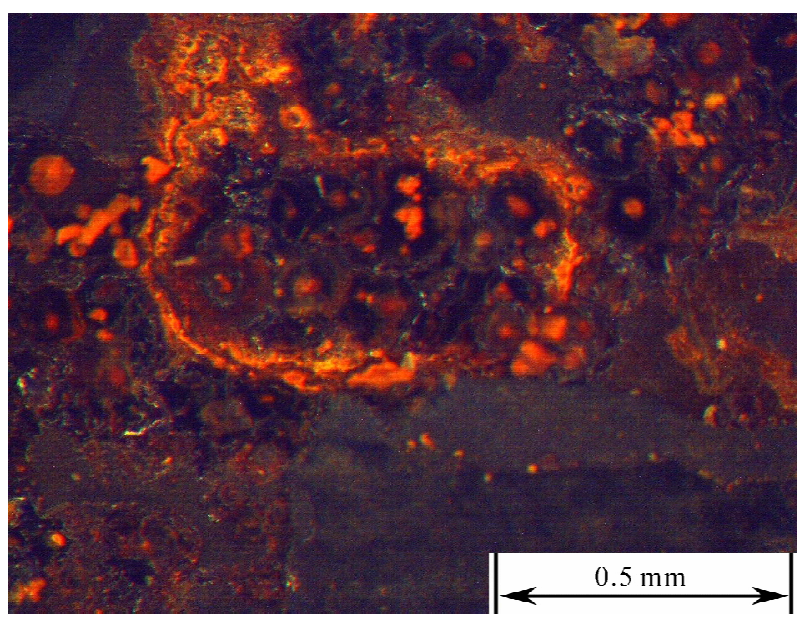

Figure 9. Photomicrograph of $1020 \mathrm{C}$ carbon steel treated at $675^{\circ} \mathrm{C}$ and after 4 days of corrosion studies in $3 \mathrm{wt} . \% \mathrm{NaCl}$ solution.

\section{Conclusions}

The results presented here show that the aqueous corrosion trends with time for the same low-carbon steel samples are different for oxidative treatments at $550^{\circ} \mathrm{C}$ and $675^{\circ} \mathrm{C}$. While the sample treated at $550^{\circ} \mathrm{C}$ resulted in increasing corrosion rates with time for the 4-day experimental period, the sample treated at $675^{\circ} \mathrm{C}$ presented a decreasing rate of corrosion over the same experimental period.

The corrosion behavior observed for the $675^{\circ} \mathrm{C}$ sample was closer to that of the untreated sample than that of the sample treated at $550^{\circ} \mathrm{C}$. This was unexpected. The results clearly suggest that the effects of oxidative high temperature treatments on the corrosion behavior and 
surface developments of low-carbon steels, and presumably on all structural steels, is more complex than the simple expectation of increased porous surface oxide formation. For example, Bautista et al. [11], in a recent study of the corrosion behavior of sintered ferritic stainless steels after high temperature $\left(800^{\circ} \mathrm{C}\right)$ treatment, reported that while high temperature exposures resulted in an increase in the corrosion current density for $11.3 \mathrm{wt} . \%$ $\mathrm{Cr}$ ferritic stainless steel, a similar treatment for a 16.7 wt.\% $\mathrm{Cr}$ stainless steel sample resulted in a decrease in the corrosion current density as compared to the untreated samples.

These results clearly demonstrate that the exact influence of elevated temperatures on the corrosion behavior of structural steels is still not fully understood. Perhaps, a full understanding of temperature effects on the corrosion behavior of structural materials in general lies in the nanostructure developments that accompany such temperature treatments, and other extreme conditions such as pressure, fluids dynamics, irradiation, etc. The study of the relationships between nanostructure developments of these materials under extreme environments and at different temporal scales, deserve additional research emphasis. Unfortunately, a major factor militating against such efforts is the lack of appropriate in-situ experimental techniques and adequate nanoscale analytical capabilities that could facilitate such nanoscale studies on structural steel materials.

\section{Acknowledgements}

The authors would like to acknowledge the financial support of the Department of Energy-National Nuclear Security Administration (DOE-NNSA) under the Samuel Massie Chair of Excellence program.

\section{REFERENCES}

[1] A. Talekar, D. Chandra, R. Chellapa, J. Daemen, N. Tamura and M. Kunz, "Oxidation Kinetics of High Strength Low Alloy Steels at Elevated Temperatures," Corrosion Science, Vol. 50, No. 10, 2008, pp. 2804-2815. doi:10.1016/i.corsci.2008.08.008

[2] F. Velasco, A. Bautista and A. Gonzalez-Centeno, "HighTemperature Oxidation and Aqueous Corrosion Performance of Ferritic, Vacuum-Sintered Stainless Steels Prealloyed with Si," Corrosion Science, Vol. 51, No. 1,
2009, pp. 21-27. doi:10.1016/j.corsci.2008.09.035

[3] Y. Ashida, L. G. McMillin and G. Taylor, "The Effect of Temperature Oscillation on the Passive Corrosion Properties of Alloy 22," Electrochemistry Communications, Vol. 9, No. 5, 2007, pp. 1102-1106. doi:10.1016/j.elecom.2007.01.006

[4] US Department of Energy, Office of Science, "Basic Research Needs for Advanced Nuclear Energy Systems: Report of Basic Energy Sciences Workshop," Washington DC, 2006, pp. 113-120.

[5] US Department of Energy, Office of Science, "Materials Under Extreme Environments: Report of Basic Energy Sciences Workshop," Washington DC, 2007, pp. 83-89.

[6] M. J. Alinger, G. R. Odette and D. T. Hoelzer, "The Development and Stability of Y-Ti-O Nanoclusters in Mechanically Alloyed Fe-Cr Based Ferritic Alloys," Journal of Nuclear Materials, Vol. 329-333, 2004, pp. 382-386. doi:10.1016/j.jnucmat.2004.04.042

[7] W. F. Wang and M. J. Wu, "Effect of Silicon Content and Aging Time on Density, Hardness, Toughness and Corrosion Resistance of Sintered 303LSC-Si Stainless Steels," Materials Science and Engineering: A, Vol. 425, No. 1-2, 2006, pp. 167-171. doi:10.1016/j.msea.2006.03.050

[8] W. T. Tsai, Y. N. Wen, J. T. Lee, H. Y. liou and W. F. Wang, "Effect of Silicon Addition on the Microstructure and Corrosion Behavior of Sintered Stainless Steel," Surface and Coatings Technology, Vol. 34, No. 3, 1988, pp. 209-217. doi:10.1016/0257-8972(88)90113-2

[9] T. K. Rout, "Electrochemical Impedance Spectroscopy Study on Multi-Layered Coated Steel Sheets," Corrosion Science, Vol. 49, No. 2, 2007, pp. 794-817. doi:10.1016/j.corsci.2006.06.008

[10] X. Zhao, Y. Zuo, J. Zhao, J. Xiong and Y. Tang, "A Study on the Self-Sealing Process of Anodic Films on Aluminum by EIS," Surface and Coatings Technology, Vol. 200, No. 24, 2006, pp. 6846-6853. doi:10.1016/j.surfcoat.2005.10.031

[11] A. Bautista, A. Gonzalez-Centeno, G. Blanco and S. Guzman, "Application of EIS to the Study of Corrosion Behavior of Sintered Ferritic Stainless Steels before and after High-Temperature Exposure," Materials Characterization, Vol. 59, No. 1, 2008, pp. 32-39. doi:10.1016/j.matchar.2006.10.008 